\title{
Association of Gait With Global and Domain-specific Cognitive Function Among Community-dwelling Older Adults: A Cross-sectional Study
}

\section{WEN HAO}

Hokkaido University Graduate School of Medicine

\section{Wenjing Zhao}

Hokkaido University Graduate School of Medicine

\section{Takashi Kimura}

Hokkaido University Graduate School of Medicine

Shigekazu Ukawa

Osaka City University

\section{Ken Kadoya}

Hokkaido University Graduate School of Medicine

Katsunori Kondo

Chiba University

Akiko Tamakoshi ( $\nabla$ tamaa@med.hokudai.ac.jp)

Hokkaido University Graduate School of Medicine

\section{Research Article}

Keywords: aged, dementia, gait, cognition, executive function, factor analysis

Posted Date: April 27th, 2021

DOI: https://doi.org/10.21203/rs.3.rs-439336/v1

License: (a) (i) This work is licensed under a Creative Commons Attribution 4.0 International License. Read Full License 


\section{Abstract}

Background: Gait is associated with cognitive function and is a trait marker of dementia; however, research on gait and cognitive function usually concentrates on several individual gait parameters. This study used wearable sensors to measure gait parameters in different aspects and comprehensively explored the association of gait with global cognitive function and domain-specific cognitive function.

Methods: The data of this cross-sectional study were obtained from 236 community-dwelling Japanese older adults (125 men and 111 women) aged $70-81$ years. Gait was measured by asking participants to walk a 6-meter course and back using the Physilog ${ }^{\circledR}$ sensors (GaiUp ${ }^{\circledR}$, Switzerland). Global cognitive function and cognitive domains were evaluated by face-to-face interviews using the Japanese version of the Montreal Cognitive Assessment. Twenty gait parameters were summarized as independent gait factors using factor analysis. A generalized linear model and linear regression model were used to explore the relationship of gait with global cognitive function and domain-specific cognitive function adjusted for several confounding factors.

Results: Factor analysis yielded four gait factors: general cycle, initial contact, propulsion, and mid-swing. Among them, general cycle factor was significantly associated with global cognitive function $(\beta=-0.565$, $[-0.967,-0.163])$, executive function $(P=0.012)$, and memory $(P=0.045)$; initial contact was associated with executive function $(P=0.019)$.

Conclusion: Better gait was related to better cognitive function, especially the general cycle, which was correlated with both global and domain-specific cognitive function. The predictive value should be examined in future cohort studies.

\section{Background}

Approximately 50 million people have dementia worldwide, and nearly 10 million new cases are diagnosed every year. It is predicted in Japan, with the world's fastest aging population, will have close to $9 \%$ of the population with dementia by 2050 [1]. Dementia is typically diagnosed when acquired cognitive functional impairment is severe enough to compromise social and occupational functioning [2]. Patients exhibit symptoms, such as new forgetfulness, more trouble understanding spoken and written communication, difficulty finding words, and not knowing common facts [3]. Both a rapid increase in the number of people living with dementia and its clinical features contribute to increasing the societal burden [1]. However, the early diagnosis of dementia can ease these burdens by helping patients live independently and using less long-term care services [4]. Emerging evidence indicates that gait has the potential to serve as a trait marker of dementia because of its close relationship with early cognitive functional impairment [5].

Gait is the most important method of human locomotion, characterized by periods of loading and unloading of the limbs to move around and provide independence [6]. Usually, it incorporates several measurable gait parameters, such as speed, stride length, stride width, and cadence. 
Several individual gait parameters are significantly correlated with global cognitive function in older adults, including preferred gait speed [7, 8], maximum gait speed [9], and stride length [10]. Moreover, some studies have demonstrated that gait is related to domain-specific cognitive function. For instance, impaired gait velocity and reduced cadence are associated with worse executive function and immediate memory [11]. The mean walking speed and maximum walking speed are significantly associated with the attention domain [12].

Nevertheless, gait is multidimensional and cannot be evaluated by a single characteristic. A single parameter applied before could not show a comprehensive association between gait and cognitive function. Recently, a wearable sensor has been invented that can measure gait from general, temporal, visual, and clearance aspects, while simultaneously allowing people to walk in a natural environment. Moreover, based on the knowledge that quantitative gait parameters are highly correlated with each other and their individual relationships with cognitive function may be difficult to observe while adjusting for other gait variables [13], conceptual models using principal component analysis or factor analysis to provide a simplified framework for selecting grouped gait factors were suggested in gait analysis [14]. Under these circumstances, research that includes gait parameters from different aspects and uses a conceptual model for systemically analyzing gait and cognitive function is scarce.

Therefore, by adopting a more advanced sensor, we aimed to examine comprehensively the associations between gait and cognitive function to make gait a more plausible marker of dementia.

\section{Methods}

\section{Participants}

The data for this research were obtained from the Cognition and Activity in Rural Environment of HokkaiDO Senior (CARE-DO) study 2018, which was conducted after the Japan Gerontological Evaluation Study 2016. The Japan Gerontological Evaluation Study is a large panel study directed at understanding the health, social, and behavioral issues among the older population in Japan [15]. In the Japan Gerontological Evaluation Study 2016 wave, more than 200,000 citizens who did not receive long-term care insurance from 39 cities were included. Among them, 5013 community-dwelling Hokkaido residents aged between 69 and 80 years were invited to attend the CARE-DO Study in winter 2017, and 569 participants who responded to the winter survey in 2017 were subsequently invited to the CARE-DO summer study in September and October 2018. A total of 309 participants who attended were regarded as the participants of this study.

The CARE-DO Study 2018 included four main parts: physical examinations, gait and cognitive assessments, and a self-administered questionnaire. Height was measured using the corresponding scale during the physical examination. After the participants completed all assessments, a self-administered questionnaire that contained information on age, sex, and history of diseases, such as diabetes (yes or no) and hypertension (yes or no), were allocated to each of them and expected to be sent back after 2 weeks. After excluding 21 participants with missing data on cognitive and gait assessments; one with depression; three with Parkinson's disease or Alzheimer's disease; five with stroke; 35 with musculoskeletal pain; and eight 
who once fell down or had a bone fracture; 236 participants were regarded as valid participants and were included in the data analysis process (Fig. 1).

This study was approved by the ethics committee of the Graduate School of Medicine, Hokkaido University (no.18-025), all the experiment protocol for involving human data was in accordance with the relevant guidelines. A written informed consent was obtained from all the participants.

\section{Gait measurement}

All participants were asked to walk a round trip of a 6-meter straight path at a self-selected walking speed. Gait was measured using Physilog ${ }^{\circledR}$ sensors (GaiUp ${ }^{\circledR}$, Switzerland), which consist of two small, lightweight $(19 \mathrm{~g})$, inertial sensors for each foot, and elastic straps to attach the sensors to the dorsum of the foot, and Gait Analyzer software version 3.1 (GaitUp) running on a Windows personal computer. Two sensors on both the feet could be synchronized wirelessly, and no calibration procedure was required before and during the measurement. The position of the sensor on the foot did not affect the measurements [16]. The following 21 kinematic gait parameters from four aspects could be obtained through this device: general (cycle generation, cadence, stride time, stride velocity, and turning angle); temporal (stance, swing, loading, foot-flat, pushing, and double support); spatial (peak angle velocity, swing speed, strike angle, lift-off angle, swing width, and three-dimensional (3D) path length); and clearance (maximum heel clearance, maximum toe clearance 1, minimum toe clearance, and max toe clearance 2 ). As gait cycle duration is just a different format of cadence, the parameter of gait cycle duration was excluded before the analysis. The data at the time of accelerating or decelerating and making a turn were excluded by the default function of the Gait Analyzer. The mean values of two feet were used. Detailed descriptions of these parameters cis provided in Additional file1.

\section{Cognition measurement}

Global cognitive function was evaluated using the Japanese version of the Montreal Cognitive Assessment (MoCA-J) through face-to-face interviews. The MoCA-J is a one-page 30-point test administered in approximately 15 min by trained investigators, and higher scores represent better cognitive function. To regulate the effect of education, participants with an educational background of less than 12 years were asked to add one score to the total score. The MoCA-J can assess the following six cognitive domains: memory (five points): delayed recall; executive function (four points): letter fluency, trial making, verbal abstraction; visuospatial (four points): cube copy, clock drawing; languages (five points): naming, sentence repetition; attention (six points): digit span forward and backward, letter A tapping, serial-7 subtraction; and orientation (six points): orientation of date and place [17].

\section{Statistical analysis}

The chi-square test was used to compare the categorical variables, and a one-way analysis of variance was used to compare the continuous variables.

All 20 continuous gait parameters were standardized to have a mean of 0 and a standard deviation of one because of the different scales before analysis. Subsequently, factor analysis using the principal component method was performed to reduce the larger number of highly correlated variables to a smaller number of 
uncorrelated independent predictors. The initial factors were subjected to an orthogonal quartimax rotation. Gait parameters with a rotated loading of $>0.5$ were considered as the dominant contributors to the main factors. The name was labeled according to the interpretation of the original gait parameters.

A generalized linear model was used to identify the relationship between the MoCA-J score and retained gait factors in all the participants and both sexes. Due to the total score of each cognitive domain was small and direct adoption of the linear regression model may cause bias, tertile was made for each gait factor. The mean value of each group was adjusted for age, sex, height, and education as the least square mean value. $P$ for trends were tested by linear regression model, in all the participants and both sexes, test for trend based on variable containing median value for each tertile. The main confounding factors in this study were age, sex, height, educational status, diabetes, and hypertension. Statistical significance was set at $P<0.05$. All statistical analyses were performed using the SAS software (version 9.4; SAS Institute Inc., Cary, NC, USA).

\section{Results}

The study included 125 men and 111 women with an average age of 75.28 years and 75.53 years, respectively. Approximately $45 \%$ of the patients had hypertension and $14 \%$ had diabetes. In gait assessments, women had significantly shorter stride length, quicker cadence, and shorter stance period than men. In cognitive measurements, women performed significantly better on memory (Table 1). 
Table 1

Characteristics of participants according to sex

\begin{tabular}{|c|c|c|c|c|c|c|}
\hline \multirow{2}{*}{ Age (years) } & & \multicolumn{2}{|c|}{ Men $(n=132)$} & \multicolumn{2}{|c|}{ Women $(n=111)$} & \multirow{2}{*}{$\begin{array}{l}P \\
0.658^{\dagger}\end{array}$} \\
\hline & & 75.28 & $(2.84)$ & 75.53 & $(2.81)$ & \\
\hline Height (m) & mean (SD) & 162.99 & $(5.08)$ & 150.63 & $(5.22)$ & $<0.001^{\dagger}$ \\
\hline 12 years of education & $\mathrm{n}(\%)$ & 35 & (15) & 16 & (7) & $0.014^{\ddagger}$ \\
\hline \multicolumn{7}{|l|}{ Gait measurements } \\
\hline stride length (m) & mean (SD) & 1.08 & $(0.12)$ & 1.02 & $(0.14)$ & $0.005^{\dagger}$ \\
\hline speed $(\mathrm{m} / \mathrm{s})$ & mean (SD) & 0.98 & $(0.16)$ & 1.00 & $(0.17)$ & $0.274^{\dagger}$ \\
\hline cadence (steps/min) & mean $(S D)$ & 110.47 & $(8.89)$ & 117.91 & $(11.81)$ & $<0.001^{\dagger}$ \\
\hline stance (s) & mean (SD) & 0.68 & $(0.07)$ & 0.65 & $(0.09)$ & $<0.001^{\dagger}$ \\
\hline \multicolumn{7}{|l|}{ History of diseases } \\
\hline Hypertension & $\mathrm{n}(\%)$ & 61 & (26) & 46 & (19) & $0.433^{\ddagger}$ \\
\hline Diabetes & $\mathrm{n}(\%)$ & 21 & (9) & 11 & (5) & $0.136^{\ddagger}$ \\
\hline \multicolumn{7}{|c|}{ Cognitive measurements } \\
\hline MoCA-J (points) & mean (SD) & 23.08 & $(3.26)$ & 23.68 & $(3.12)$ & $0.476^{\dagger}$ \\
\hline executive $(0-4)$ & mean (SD) & 2.74 & $(0.99)$ & 2.73 & $(1.03)$ & $0.962^{\dagger}$ \\
\hline language $(0-5)$ & mean $(S D)$ & 3.82 & $(0.79)$ & 3.70 & $(0.73)$ & $0.293^{\dagger}$ \\
\hline memory $(0-5)$ & mean (SD) & 2.43 & $(1.71)$ & 3.13 & $(1.66)$ & $<0.001^{+}$ \\
\hline orientation $(0-6)$ & mean (SD) & 5.70 & $(0.58)$ & 5.77 & $(0.62)$ & $0.307^{\dagger}$ \\
\hline visuospatial $(0-4)$ & mean (SD) & 2.61 & $(0.71)$ & 2.62 & $(0.7)$ & $0.707^{\dagger}$ \\
\hline attention $(0-6)$ & mean (SD) & 5.05 & $(1.15)$ & 4.88 & $(1.06)$ & $0.275^{\dagger}$ \\
\hline \multicolumn{7}{|c|}{ Bolded $P$-values indicate $P<0.05$} \\
\hline \multicolumn{7}{|c|}{ MoCA-J, Japanese version of Montreal Cognitive Assessment; SD, standard deviation } \\
\hline
\end{tabular}

Factor analysis with quartimax rotation yielded exactly four orthogonal factors that accounted for $89.17 \%$ of the variance in 20 gait parameters (Table 2). The factor with the highest variance had strong loadings on stance, cadence, foot-flat, stride velocity, double support, swing, swing speed and peak angle velocity and was termed "general cycle" factor. The second factor reflecting the strike angle, maximum toe clearance 
stride length loading, and 3D path length was named "initial contact" factor. The third factor loaded on pushing and lift-off angle was termed "propulsion" factor. The final factor loaded heavily on maximum heel clearance and maximum toe clearance and was called "mid-swing" factor (Fig. 2). A lower score for the general cycle factor and propulsion factor represented better gait, and a higher score of initial contact and mid-swing factor represented better gait.

Table 2

Factor loadings of 20 gait variables on four independent gait factors extracted by factor analysis

\begin{tabular}{|c|c|c|c|c|}
\hline Gait variable & General cycle & Initial contact & Propulsion & Mid-swing \\
\hline Stance (s) & 0.97 & & & \\
\hline Cadence (steps/min) & -0.95 & & & \\
\hline Foot-flat (s) & 0.90 & & & \\
\hline Stride velocity $(\mathrm{m} / \mathrm{s})$ & -0.82 & & & \\
\hline Double support (s) & 0.80 & & & \\
\hline Swing (s) & 0.75 & & & \\
\hline Swing speed $(\mathrm{m} / \mathrm{s})$ & -0.75 & & & \\
\hline Peak angle velocity (degree/s) & -0.74 & & & \\
\hline Strike angle (degree) & & 0.91 & & \\
\hline Stride length $(m)$ & & 0.83 & & \\
\hline Maximum toe clearance $2(\mathrm{~m})$ & & 0.83 & & \\
\hline 3D path length (meters) & & 0.79 & & \\
\hline Loading (s) & & 0.69 & & \\
\hline Pushing (s) & & & 0.89 & \\
\hline Lift-off angle (degree) & & & 0.68 & \\
\hline Maximum heel clearance $(\mathrm{m})$ & & & & 0.84 \\
\hline Maximum toe clearance $1(\mathrm{~m})$ & & & & 0.83 \\
\hline Variance explained (\%) & 43.27 & 24.56 & 13.31 & 8.03 \\
\hline
\end{tabular}

\section{Gait and global cognitive function}

Of the four gait factors, general cycle and propulsion factor had a negative association with the MoCA-J score, and initial contact and mid-swing factor had a positive association with MoCA-J score. The general cycle factor showed significant associations with global cognitive function in the crude model $(\beta=-0.674$ 
$[-1.074,-0.274])$; model adjusted for age, sex, and height ( $\beta=-0.566,[-0.968,-0.164])$; and model adjusted for age, sex, height, diabetes, and hypertension $(\beta=-0.565,[-0.967,-0.163])$ of all the participants. The factor of the general cycle was also significantly associated with global cognition in the crude model $(\beta=-0.827$ $[-1.357,-0.296]) ;$ model adjusted for age and height ( $\beta=-0.772,[-1.298,-0.246])$; and model adjusted for age, height, education, diabetes, and hypertension ( $\beta=-0.763,[-1.289,-0.237])$. In men, significance was found neither in the crude model nor in the adjusted models (Table 3 ). 
Table 3

Associations between gait factors and the MoCA-J score in all participants and both sexes
Total
Women
Men

\begin{tabular}{|c|c|c|c|c|c|}
\hline Model & $\beta$ & $\begin{array}{l}\text { Wald } 95 \% \\
\text { Confidence limits }\end{array}$ & $\beta$ & $\begin{array}{l}\text { Wald 95\% } \\
\text { Confidence } \\
\text { limits }\end{array}$ & $\beta$ \\
\hline
\end{tabular}

Model $1^{\dagger}$

$\begin{array}{llllllllll}\begin{array}{l}\text { General } \\ \text { cycle }\end{array} & -0.674 \star \star \star & -1.074 & -0.274 & -0.827^{\star \star} & -1.357 & -0.296 & -0.403 & -1.046 & 0.240 \\ \begin{array}{l}\text { Initial } \\ \text { contact }\end{array} & 0.232 & -0.180 & 0.645 & 0.343 & -0.269 & 0.955 & 0.328 & -0.260 & 0.916\end{array}$

$\begin{array}{llllllllll}\text { Propulsion } & -0.038 & -0.453 & 0.376 & -0.343 & -0.949 & 0.264 & 0.011 & -0.623 & 0.644\end{array}$

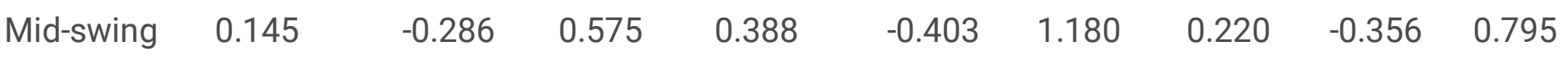

Model $2^{\ddagger}$

$\begin{array}{lccccccccc}\begin{array}{l}\text { General } \\ \text { cycle }\end{array} & -0.566^{\star \star} & -0.968 & -0.164 & -0.772^{\star \star} & -1.298 & -0.246 & -0.368 & -0.987 & 0.251 \\ \begin{array}{l}\text { Initial } \\ \text { contact }\end{array} & 0.122 & -0.297 & 0.541 & 0.190 & -0.434 & 0.813 & 0.089 & -0.473 & 0.651\end{array}$

\begin{tabular}{llllllllll} 
Propulsion & -0.145 & -0.568 & 0.278 & -0.360 & -0.959 & 0.240 & 0.071 & -0.518 & 0.660 \\
\hline Mid-swing & 0.098 & -0.350 & 0.547 & 0.302 & -0.506 & 1.109 & -0.028 & -0.563 & 0.508
\end{tabular}

Model $3 \S$

\begin{tabular}{llllllllll}
$\begin{array}{l}\text { General } \\
\text { cycle }\end{array}$ & $-0.565^{\star \star}$ & -0.967 & -0.163 & $-0.763^{\star \star}$ & -1.289 & -0.237 & -0.367 & -0.986 & 0.252 \\
$\begin{array}{l}\text { Initial } \\
\text { contact }\end{array}$ & 0.116 & -0.305 & 0.538 & 0.171 & -0.454 & 0.796 & 0.091 & -0.476 & 0.658 \\
\hline Propulsion & -0.154 & -0.579 & 0.271 & -0.370 & -0.970 & 0.231 & 0.074 & -0.521 & 0.669 \\
\hline Mid-swing & 0.101 & -0.352 & 0.555 & 0.303 & -0.522 & 1.127 & -0.037 & -0.578 & 0.504
\end{tabular}

MoCA-J, Japanese version of Montreal Cognitive Assessment

${ }^{\dagger}$ Model 1 crude model

${ }^{\ddagger}$ Model 2 adjusted for age, sex, and height

$\S$ Model 3 adjusted for age, sex, height, diabetes and hypertension

** $P<0.01, * \star * P<0.001$ 
Of the six cognitive domains, significant differences were found in the general cycle factor $(P=0.012)$, initial contact factor $(P=0.019)$ with executive domain, and general cycle factor with memory domain $(P=0.045)$. Better performance of the general cycle and initial contact was correlated with higher scores of executive function. Better performance of the general cycle factor was correlated with a better memory domain (Table 4). Men and women showed different results. Better performance of initial contact was related to higher scores of executive function in women (Additional Table 2); no significant relationship was found between gait and specific domain in men (Additional Table 3).

Table 4

Adjusted means of domain-specific cognitive function by tertile of each gait factor in all the participants

\begin{tabular}{|c|c|c|c|c|c|c|c|}
\hline Factor & & $\begin{array}{l}\text { Executive } \\
\text { function }\end{array}$ & Language & Memory & Orientation & Visuospatial & Attention \\
\hline \multirow{3}{*}{$\begin{array}{l}\text { General } \\
\text { cycle }\end{array}$} & Low & 2.91 & 3.70 & 2.93 & 5.75 & 2.58 & 5.09 \\
\hline & Moderate & 2.76 & 3.79 & 2.78 & 5.80 & 2.69 & 4.93 \\
\hline & High & 2.54 & 3.81 & 2.57 & 5.65 & 2.57 & 4.89 \\
\hline$P$ for trend & & 0.012 & 0.654 & 0.045 & 0.264 & 0.875 & 0.304 \\
\hline \multirow{3}{*}{$\begin{array}{l}\text { Initial } \\
\text { contact }\end{array}$} & Low & 2.53 & 3.84 & 2.74 & 5.74 & 2.58 & 4.96 \\
\hline & Moderate & 2.72 & 3.76 & 2.77 & 5.71 & 2.64 & 4.92 \\
\hline & High & 2.96 & 3.70 & 2.77 & 5.75 & 2.63 & 5.03 \\
\hline$P$ for trend & & 0.019 & 0.240 & 0.993 & 0.979 & 0.764 & 0.636 \\
\hline \multirow[t]{3}{*}{ Propulsion } & Low & 2.80 & 3.68 & 2.82 & 5.70 & 2.61 & 5.07 \\
\hline & Moderate & 2.66 & 3.91 & 2.60 & 5.83 & 2.64 & 4.91 \\
\hline & High & 2.75 & 3.71 & 2.85 & 5.67 & 2.60 & 4.94 \\
\hline$P$ for trend & & 0.943 & 0.508 & 0.503 & 0.824 & 0.849 & 0.558 \\
\hline \multirow[t]{3}{*}{ Mid-swing } & Low & 2.56 & 3.70 & 2.87 & 5.61 & 2.54 & 4.91 \\
\hline & Moderate & 2.85 & 3.86 & 2.64 & 5.79 & 2.74 & 5.03 \\
\hline & High & 2.79 & 3.73 & 2.76 & 5.79 & 2.56 & 4.97 \\
\hline$P$ for trend & & 0.2179 & 0.870 & 0.598 & 0.103 & 0.646 & 0.968 \\
\hline
\end{tabular}

\section{Discussion}

Our study found that among older adults aged 70-81 years, the general cycle is most associated with global cognitive function; when cognitive function is specified in domains, results showed better general cycle and 
initial contact phase related to better executive function, the general cycle phase was also related to the memory domain.

To the best of our knowledge, this is the first study to include most of the various gait parameters that almost consist of the whole gait phase when studying the association between gait and cognitive function. To date, various techniques have been used in gait analysis, including stopwatches, electronic walkways, body-worn sensors, electromyography, and 3D motion analysis $[6,14]$. The technique used in this study was an easily wearable sensor that measured 3D gait. The 3D motion analysis is considered accurate and is used as the gold standard in gait analysis [18]. Moreover, we used conceptual models to summarize various parameters of gait factors. Previous studies have also used a conceptual model [13, 14, 19-21]; however, gait assessments in all those articles were performed using a walkway (GAITRite, CIR System Inc.). The nature of walkways determined that it can only assess general (velocity, width, cadence, and stride time) and temporal (time for swing, stance, single and double support, and turning) parameters, while those used in this study could additionally evaluate gait from spatial and clearance aspects, benefit from further factors of initial contact, propulsion, and mid-swing were output, which made the gait analysis more comprehensive. Hence, compared to most other studies using simple techniques, our results are more precise and show a complete relationship between gait and cognitive function.

After adjusting for several confounders, the results showed that only general cycle factors (predominantly cadence, speed, and stance time) were significantly associated with global cognitive function in all the participants. People with lower scores for the general cycle factor were inclined to have higher MoCA-J scores. Internal biomechanism can be referred to as the proved mechanism between gait speed and cognitive function. Some lesions of the brain, such as an increased proportion of the periventricular and subcortical white matter hyperintensities, atrophy of the medial temporal areas, hippocampal atrophy [22], or small gray matter volumes in the bilateral cortical and subcortical regions, based on magnetic resonance imaging [23] can slow the gait speed, while simultaneously impairing cognitive function. In addition, recent studies have started researching the biomechanism between other parameters and cognitive function; for example, higher cerebral amyloid- $\beta$ deposition was shown to be associated with increased double support time [24]. Therefore, by involving more gait aspects, a more robust mechanism could be clear between gait and cognitive function.

With respect to newly invented factors of initial contact, propulsion, and mid-swing, no significance was found for global cognitive function. Although previous studies claimed that the contributor of stride length in the initial contact factor was related to cognitive function [25], their relationship was probably caused by the high correlation with gait speed. In addition, according to a study of brain dynamics while walking, electrocortical activity progressively decreases in the pre-swing phase and acceleration phase [26], which indicates that compared to the preparatory phases for the most important point of walking, the general cycle factor that includes characteristics of posture control (double support and foot-flat) is better associated with global cognitive function.

Further exploration of domain-specific cognitive function supported the strong association between executive function and gait $[27,28]$. The term executive function refers to the higher-level cognitive skills we

Page $11 / 19$ 
use to control and coordinate our other cognitive abilities and behaviors [29] traditionally, it is associated with the frontal lobes and related brain networks, in particular, the dorsolateral prefrontal cortex and cingulate cortex [30]. A previous study found that gait shared similar brain regions in which a great burden of subcortical white matter hyperintensities on magnetic resonance imaging is related to increased dual-task costs while walking [31], which could be the main reason for their high correlation. In addition, past studies have suggested that gait requires memory; shared anatomy can also be used to explain their robust relationship [32]. However, some individual gait parameters have a significant relationship with language and attention domain [33]. After being detained by the factor analysis, combined gait characteristics did not show any relationship with other domains except for executive function and memory domain. Therefore, enough evidence for an association between gait and the other two domains, orientation and visuospatial, in all the participants was not found [34].

Moreover, our results varied greatly in terms of sex. According to basic characteristics, men performed worse on both gait and cognitive assessment than women, which is proved by the previous studies that older women usually outperformed on the test of motor speed [35] and memory than men despite the same level of cognitive degeneration [36, 37]. Moreover, women showed a stronger relationship between gait and global cognitive function, and no significance relationship was observed in men. The cognitive benefit of physical activity may be greater in women than in men [38]; however, the effect and biological mechanism of sex on the relationship between gait and cognitive function remains unclear. These observations illustrate that sex difference is an important confounding factor in the study of gait and cognitive function among older adults, and it should be discussed in future work.

This study has both strengths and limitations. Although the advanced device and conceptual models used in this study makes it more comprehensive and precise, the following aspects still warrant some attention: first, this was a cross-sectional study, which meant that the causality between gait and cognitive function could not be determined. Second, during the process of measuring gait parameters, the first and last two cycles were not excluded given the short total distance, while the initiation and termination of gait are sometimes thought to be unstable and inaccurate [39]. As claimed by other studies, older adults need at least four gait cycles to reach steady-state walking speed [40]. Third, only the MoCA-J questionnaire was used in the cognitive assessment procedure, although the MoCA was identified as an applicable method for evaluating global and domain-specific cognition, a previous study claimed that the MoCA is not comparatively sensitive or specific for identifying attention or language impairments $[41,42]$. To maintain the veracity of cognitive function, especially in the study of exploring different cognitive domains, extensive neuropsychological batteries should be added in the future research. Finally, the participants in our study were older than 70 years, and $70 \%$ of them had mild cognitive impairment $(\mathrm{MCl})(\mathrm{MoCA}<26$ is defined as $\mathrm{MCl}$ [43]). However, the prevalence of $\mathrm{MCl}$ among older adults usually ranges between $3 \%$ and $42 \%$ [44]. Atypical $\mathrm{MCl}$ prevalence may be associated with potential physical functional impairments and disease history of the participants, which we did not exclude before analysis, and this may make it difficult to generalize the results to a wider population.

\section{Conclusion}


This cross-sectional study used advanced gait measurement and found that better gait indicated better performance of cognitive function among community-dwelling older adults aged between 70 and 81 years. In particular, the general cycle was significantly correlated with global cognitive function, executive function, and memory, and the initial contact factor was related to executive function. In the future, longitudinal cohort research with a larger sample size and extensive neuropsychological batteries is needed to detect the causality between gait and cognitive function.

\section{Abbreviations}

CARE-DO Cognition and Activity in Rural Environment of HokkaiDO Senior

MoCA-J Japanese version of Montreal Cognitive Assessment

3D Three-dimension

MCI Mild Cognitive Impairment

\section{Declarations}

\section{Ethics approval and consent to participate}

This study was approved by the ethics committee of the Graduate School of Medicine, Hokkaido University (no.18-025). A written informed consent was obtained from all the participants.

\section{Consent for publication}

Not applicable

\section{Availability of data and materials}

The datasets used and/or analyzed during the current study are available from the corresponding author on reasonable request.

\section{Competing interests}

The authors declare that they have no competing interests

\section{Funding}

The study was supported by the Japan Society for the Promotion of Science's Grants-in-Aid for Scientific Research (B): Influence of Indoor Temperature Distribution on Health of the Elderly in Cold Climate (17H04129) and Challenging Research (Exploratory): Research on the effect of gait parameters and other modifiers on cognitive function of older adults using wearable devices (18H05389). This study was also supported by the Grant-in-Aid for Scientific Research (20319338, 22390400, 23243070, 23590786, 23790710, 24140701, 24390469, 24530698, 24653150, 24683018, 25253052, 25870881, 26882010, 17H04129) of the Japan Society for the Promotion of Science; Health Labour Sciences Research Grant, 
Comprehensive Research on Aging and Health (H26-Choju-Ippan-006, H25-Choju-Ippan-003, H25-KenkiWakate-015, H25-Irryo-Shitei-003 [Fukkou], H24-Junkanki [Syosyu]-Ippan-007) of the Japanese Ministry of Health, Labour and Welfare; a grant from the Department of Health and Human Services, National Institutes of Health, National Institute on Aging (research grant number 1R01AG042463-01A1); and a grant from the National Center for Geriatrics and Gerontology (no. 24-17, no. 24-23, no. J09KF00804).

\section{Authors' contributions}

WH contributed to the conception, analysis and interpretation of data, and preparation of manuscript. WJ contributed to the analysis and interpretation of data, preparation of manuscript, critical review and feedback. SU, KK and KK contributed to the critical review and feedback. TK contributed to the design, acquisition of data, critical review and feedback. AT contributed to the design, acquisition of data, interpretation of data, critical review and feedback. All authors read and approved the final manuscript.

\section{Acknowledgement}

We would like to thank all participants and investigators for their participation in this study, research volunteers for their invaluable donation to the research, and the research staff for their assistance. We would also like to thank Isao Yokota and Ryo Takagi for their help with statistical methods and data analysis.

\section{References}

1. Sado M, Ninomiya A, Shikimoto R, lkeda B, Baba T, Yoshimura K, et al. The estimated cost of dementia in Japan, the most aged society in the world. PLoS ONE. 2018;13. doi:10.1371/journal.pone.0206508.

2. Hugo J, Ganguli M. Dementia and Cognitive Impairment: Epidemiology, Diagnosis, and Treatment. Clin Geriatr Med. 2014;30:421-42. doi:10.1016/j.cger.2014.04.001.

3. SantaCruz K, Daniel L. Swagerty J. Early Diagnosis of Dementia. Am Fam Physician. 2001;63:703. https://www.aafp.org/afp/2001/0215/p703.html. Accessed 24 Dec 2020.

4. Rasmussen J, Langerman H. Alzheimer's Disease - Why We Need Early Diagnosis. Degener Neurol Neuromuscul Dis. 2019;9:123-30. doi:10.2147/DNND.S228939.

5. Jamour M, Becker C, Synofzik M, Maetzler W. [Gait changes as an early indicator of dementia]. Z Gerontol Geriatr. 2012;45:40-4.

6. Baker R, Esquenazi A, Benedetti MG, Desloovere K. Gait analysis: clinical facts. Eur J Phys Rehabil Med. 2016;52:560-74.

7. Lenardt MH, de Sousa JAV, Grden CRB, Betiolli SE, Carneiro NHK, Ribeiro DK de MN. Gait speed and cognitive score in elderly users of the primary care service. Rev Bras Enferm. 2015;68:1163-8.

8. Garcia-Pinillos F, Cozar-Barba M, Munoz-Jimenez M, Soto-Hermoso V, Latorre-Roman P. Gait speed in older people: an easy test for detecting cognitive impairment, functional independence, and health state. Psychogeriatr Off J Jpn Psychogeriatr Soc. 2016;16:165-71.

9. Umegaki $\mathrm{H}$, Makino T, Yanagawa M, Nakashima H, Kuzuya M, Sakurai T, et al. Maximum gait speed is associated with a wide range of cognitive functions in Japanese older adults with a Clinical Dementia 
Rating of 0.5. Geriatr Gerontol Int. 2018;18:1323-9.

10. Toots ATM, Taylor ME, Lord SR, Close JCT. Associations Between Gait Speed and Cognitive Domains in Older People with Cognitive Impairment. J Alzheimers Dis. 2019;71:S15-21. doi:10.3233/JAD-181173.

11. Valkanova V, Ebmeier KP. What can gait tell us about dementia? Review of epidemiological and neuropsychological evidence. Gait Posture. 2017;53:215-23.

12. Kaye J, Mattek N, Dodge H, Buracchio T, Austin D, Hagler S, et al. One Walk a Year to 1000 Within a Year: Continuous In-home Unobtrusive Gait Assessment of Older Adults. Gait Posture. 2012;35:197-202.

13. Verghese J, Wang C, Lipton RB, Holtzer R, Xue X. Quantitative gait dysfunction and risk of cognitive decline and dementia. J Neurol Neurosurg Psychiatry. 2007;78:929-35.

14. Lord S, Galna B, Verghese J, Coleman S, Burn D, Rochester L. Independent domains of gait in older adults and associated motor and nonmotor attributes: validation of a factor analysis approach. J Gerontol A Biol Sci Med Sci. 2013;68:820-7.

15. Kondo K, Rosenberg M, Organization WH. Advancing universal health coverage through knowledge translation for healthy ageing: lessons learnt from the Japan gerontological evaluation study. World Health Organization; 2018. https://apps.who.int/iris/handle/10665/279010. Accessed 15 Mar 2021.

16. Mariani B, Hoskovec C, Rochat S, Büla C, Penders J, Aminian K. 3D gait assessment in young and elderly subjects using foot-worn inertial sensors. J Biomech. 2010;43:2999-3006.

17. Ota O, Suzuki N. Cognitive impairment in Parkinson's disease patients evaluated by the Montreal cognitive assessment and the Mini-Metal State Examination: a multicenter study of Keio PD database. 2013. https://dl.ndl.go.jp/info:ndljp/pid/11002969. Accessed 28 Oct 2020.

18. Lord S, Galna B, Rochester L. Moving forward on gait measurement: Toward a more refined approach. Mov Disord. 2013;28:1534-43. doi:https://doi.org/10.1002/mds.25545.

19. Darweesh SKL, Licher S, Wolters FJ, Koudstaal PJ, Ikram MK, Ikram MA. Quantitative gait, cognitive decline, and incident dementia: The Rotterdam Study. Alzheimers Dement J Alzheimers Assoc. 2019;15:1264-73.

20. Hollman JH, McDade EM, Petersen RC. Normative Spatiotemporal Gait Parameters in Older Adults. Gait Posture. 2011;34:111-8. doi:10.1016/j.gaitpost.2011.03.024.

21. Verlinden VJA, van der Geest JN, Hoogendam YY, Hofman A, Breteler MMB, Ikram MA. Gait patterns in a community-dwelling population aged 50 years and older. Gait Posture. 2013;37:500-5.

22. Beauchet O, Launay CP, Sekhon H, Montembeault M, Allali G. Association of hippocampal volume with gait variability in pre-dementia and dementia stages of Alzheimer disease: Results from a crosssectional study. Exp Gerontol. 2019;115:55-61.

23. Peel NM, Alapatt LJ, Jones LV, Hubbard RE. The Association Between Gait Speed and Cognitive Status in Community-Dwelling Older People: A Systematic Review and Meta-analysis. J Gerontol Ser A. 2019;74:943-8. doi:10.1093/gerona/gly140.

24. Wennberg AMV, Lesnick TG, Schwarz CG, Savica R, Hagen CE, Roberts RO, et al. Longitudinal Association Between Brain Amyloid-Beta and Gait in the Mayo Clinic Study of Aging. J Gerontol A Biol Sci Med Sci. 2018;73:1244-50. 
25. Savica R, Wennberg AMV, Hagen C, Edwards K, Roberts RO, Hollman JH, et al. Comparison of Gait Parameters for Predicting Cognitive Decline: The Mayo Clinic Study of Aging. J Alzheimers Dis JAD. 2017;55:559-67.

26. Pauw KD, Cherelle P, Tassignon B, Cutsem JV, Roelands B, Marulanda FG, et al. Cognitive performance and brain dynamics during walking with a novel bionic foot: A pilot study. PLOS ONE. 2019;14:e0214711. doi:10.1371/journal.pone.0214711.

27. Cohen JA, Verghese J, Zwerling JL. Cognition and gait in older people. Maturitas. 2016;93:73-7.

28. Callisaya ML, Blizzard CL, Wood AG, Thrift AG, Wardill T, Srikanth VK. Longitudinal Relationships Between Cognitive Decline and Gait Slowing: The Tasmanian Study of Cognition and Gait. J Gerontol Ser A. 2015;70:1226-32. doi:10.1093/gerona/glv066.

29. Diamond A. Executive Functions. Annu Rev Psychol. 2013;64:135-68.

30. Yogev-Seligmann G, Hausdorff JM, Giladi N. The role of executive function and attention in gait. Mov Disord Off J Mov Disord Soc. 2008;23:329-42; quiz 472.

31. Nadkarni NK, Levine B, Mcllroy WE, Black SE. Impact of subcortical hyperintensities on dual-tasking in Alzheimer disease and aging. Alzheimer Dis Assoc Disord. 2012;26:28-35.

32. Wennberg AMV, Savica R, Mielke MM. Association between Various Brain Pathologies and Gait Disturbance. Dement Geriatr Cogn Disord. 2017;43:128-43. doi:10.1159/000456541.

33. Montero-Odasso M, Verghese J, Beauchet O, Hausdorff JM. Gait and cognition: a complementary approach to understanding brain function and the risk of falling. J Am Geriatr Soc. 2012;60:2127-36.

34. Duff K, Mold JW, Roberts MM. Walking speed and global cognition: results from the OKLAHOMA Study. Neuropsychol Dev Cogn B Aging Neuropsychol Cogn. 2008;15:31-9.

35. Munro CA, Winicki JM, Schretlen DJ, Gower EW, Turano KA, Muñoz B, et al. Sex differences in cognition in healthy elderly individuals. Neuropsychol Dev Cogn B Aging Neuropsychol Cogn. 2012;19:759-68.

36. Sundermann EE, Maki PM, Rubin LH, Lipton RB, Landau S, Biegon A. Female advantage in verbal memory. Neurology. 2016;87:1916-24. doi:10.1212/WNL.0000000000003288.

37. Sundermann EE, Biegon A, Rubin LH, Lipton RB, Mowrey W, Landau S, et al. Better verbal memory in women than men in $\mathrm{MCl}$ despite similar levels of hippocampal atrophy. Neurology. 2016;86:1368-76. doi:10.1212/WNL.0000000000002570.

38. Barha CK, Liu-Ambrose T. Exercise and the Aging Brain: Considerations for Sex Differences. Brain Plast. 2018;4:53-63. doi:10.3233/BPL-180067.

39. Ferreira F, Gago MF, Bicho E, Carvalho C, Mollaei N, Rodrigues L, et al. Gait stride-to-stride variability and foot clearance pattern analysis in Idiopathic Parkinson's Disease and Vascular Parkinsonism. J Biomech. 2019;92:98-104.

40. Lindemann U, Najafi B, Zijlstra W, Hauer K, Muche R, Becker C, et al. Distance to achieve steady state walking speed in frail elderly persons. Gait Posture. 2008;27:91-6.

41. Julayanont P, Brousseau M, Chertkow H, Phillips N, Nasreddine ZS. Montreal Cognitive Assessment Memory Index Score (MoCA-MIS) as a predictor of conversion from mild cognitive impairment to Alzheimer's disease. J Am Geriatr Soc. 2014;62:679-84. 
42. Hendershott TR, Zhu D, Llanes S, Poston KL. Domain-specific accuracy of the Montreal Cognitive Assessment subsections in Parkinson's disease. Parkinsonism Relat Disord. 2017;38:31-4.

43. Hoops S, Nazem S, Siderowf AD, Duda JE, Xie SX, Stern MB, et al. Validity of the MoCA and MMSE in the detection of $\mathrm{MCl}$ and dementia in Parkinson disease. Neurology. 2009;73:1738-45.

44. Tricco AC, Soobiah C, Lillie E, Perrier L, Chen MH, Hemmelgarn B, et al. Use of cognitive enhancers for mild cognitive impairment: protocol for a systematic review and network meta-analysis. Syst Rev. 2012;1:25.

\section{Figures}


Participants who attended JAGES 2016 and lived in Hokkaido, aged 68-79 at $2016(\mathrm{n}=5,103)$

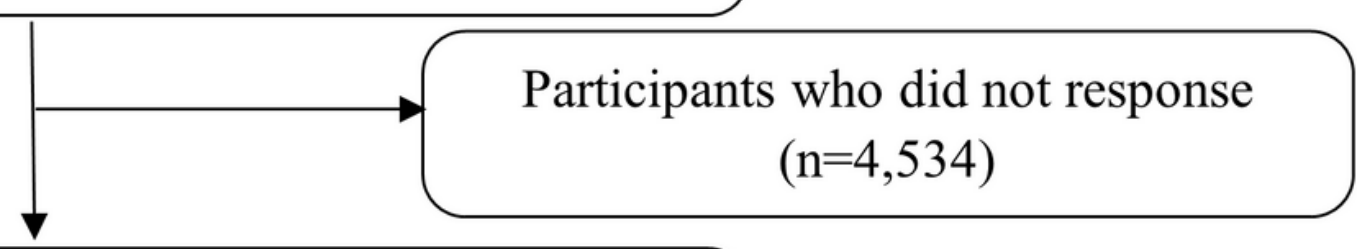

Participants who attended CARE-DO winter 2017

$$
(\mathrm{n}=569)
$$

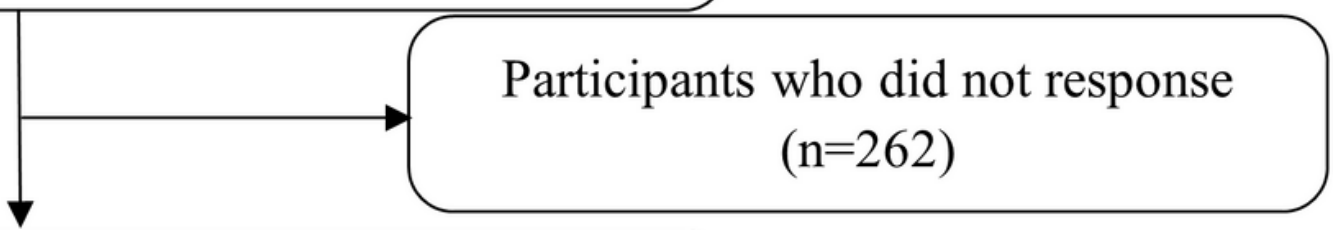

Participants who attended CARE-DO summer $2018(\mathrm{n}=309)$

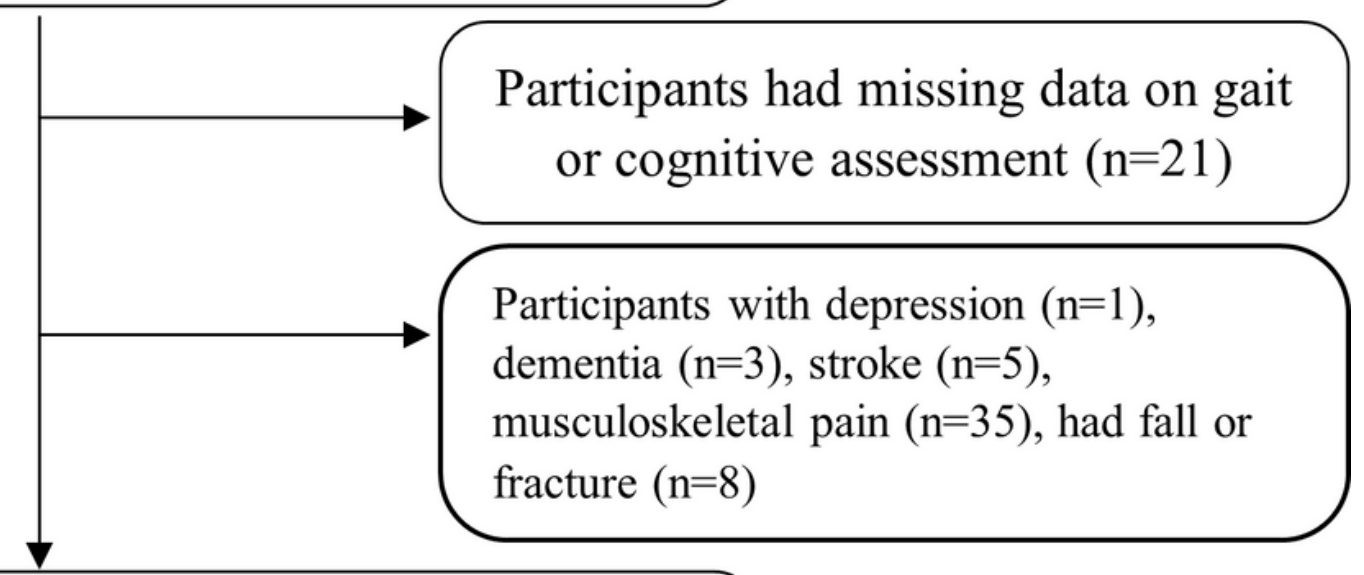

Final sample used for statistical analysis $(\mathrm{n}=236)$

\section{Figure 1}

Flowchart of study participants JAGES, the Japan Gerontological Evaluation Study; CARE-DO, Cognition and Activity in Rural Environment of HokkaiDO senior 


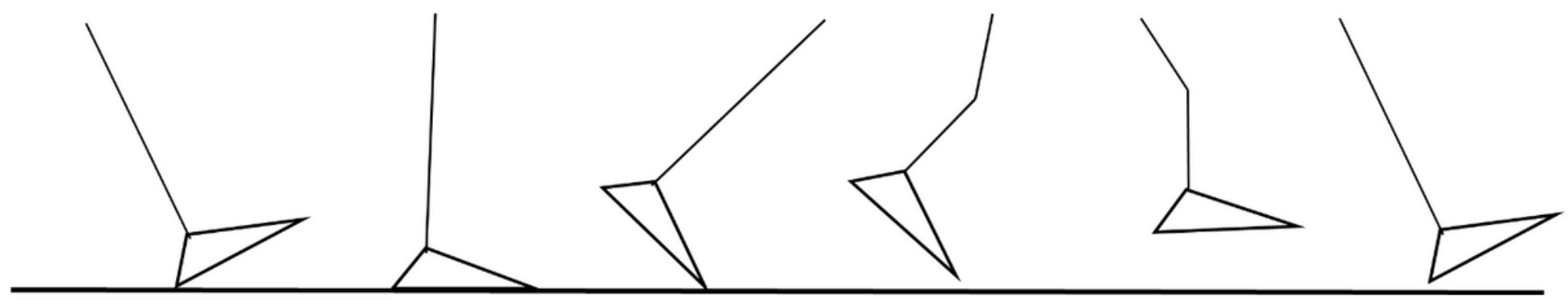

Initial contact

Propulsion

Mid-swing

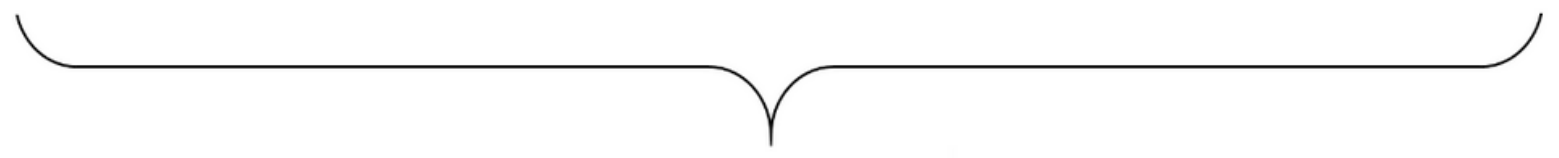

General cycle

Figure 2

Four gait factors extracted by factor analysis

\section{Supplementary Files}

This is a list of supplementary files associated with this preprint. Click to download.

- Additionalfilesgaitandcognitivefunction.docx 